\title{
A Comparative Study of Intrathecal $0.5 \%$ Hyperbaric Bupivacaine with Magnesium Sulfate versus $0.5 \%$ Hyperbaric Bupivacaine with Normal Saline in Elective Caesarean sections
}

\author{
Kishore K ${ }^{1}$, Inugala Raj Kumar Reddy ${ }^{1}$, Kalyan Kumar $\mathrm{K}^{2}$ \\ ${ }^{1}$ Associate Professor, Department of Anaesthesiology, Chalmeda Anand Rao Institute of Medical Sciences, Karimnagar, Telangana, India, ${ }^{2}$ Resident, \\ Department of Anaesthesiology, Chalmeda Anand Rao Institute of Medical Sciences, Karimnagar, Telangana, India.
}

\section{Abstract}

Background: Aim: The aim of study was to compare intrathecal $0.5 \%$ hyperbaric bupivacaine with magnesium sulfate versus $0.5 \%$ hyperbaric bupivacaine with normal saline in elective caesarian sections. Subjects and Methods: The study was cross sectional study, total sample size of 60 patients taken randomly who are undergoing Caesarean section and divided into two groups Group M (30) and Group N (30). Group M and Group N with equal number of subjects and to Group M given Inj 0.5\% hyperbaric bupivacaine $2 \mathrm{cc}(10 \mathrm{mg})+0.1 \mathrm{cc}$ of Magnesium sulfate and to Group $\mathrm{N}$ we given Inj $0.5 \%$ hyperbaric bupivacaine $2 \mathrm{cc}(10 \mathrm{mg})+0.1 \mathrm{cc}$ of Normal saline. Results: The mean age in MgSo4 + Bupivacaine group was 25.99 years and the SD was 4.22, in the Bupivacaine + Saline water group the mean age was 27.59 years and the SD was 4.56. The distribution of study samples by age groups was similar in the both groups $(\mathrm{p}=0.39)$. The mean age in the three groups is comparable $(\mathrm{t}-2.00, \mathrm{P}-$ 0.16). Conclusion: We conclude that Magnesium sulphate is very effective if used as an adjuvant to Bupivacaine in spinal anaesthesia as there is delayed onset of sensory block compared to Bupivacaine+ Normal saline, increased duration of 4 dermatome block regressions, increased duration of motor block and significant higher duration of effective analgesia without any alteration of hemodynamic parameters.

Keywords: Hyperbaric Bupivacaine, magnesium sulfate, normal Saline in elective caesarean sections

Corresponding Author: Dr. Inugala Raj Kumar Reddy, Associate Professor, Department of Anaesthesiology, Chalmeda Anand Rao Institute of Medical Sciences, Karimnagar, Telangana, India.

Received: March 2019

Accepted: April 2019

\section{Introduction}

Regional anesthesia is a safe and inexpensive technique which is widely used in caesarean section. It reduces the risk of airway complications and avoids hemodynamic changes associated with laryngoscopy and intubation. ${ }^{[1,2]}$ Spinal anaesthesia is the primary anaesthetic technique for many types of surgery. Recent developments in spinal anaesthesia have lead to greater patient satisfaction and accelerated functional recovery. ${ }^{[3]}$ currently new ways of decreasing post operative analgesic requirements are of special interest.

Recently, application of intrathecal adjuvants has gained popularity with the aim of prolonging the duration of popularity with the aim of prolonging the duration of block, of block, better success rate and patient satisfaction. Opioids such as sufentanil are commonly used as additives to local anesthetics to prolong the duration and intensify the effects of subarachnoid block. However significant side effects of opioids such as pruritus, urinary retention, respiratory depression, haemodynamic instability, occasionally severe nausea and vomiting may limit their use. It has been shown that the duration of postoperative analgesia was prolonged when magnesium is given as an adjunct for peripheral nerve block. ${ }^{[3-6]}$

\section{Subjects and Methods}

\section{Study Design}

This study was a cross sectional study, total sample size of 60 patients taken randomly who are undergoing Caesarean section and divided into two groups Group $\mathrm{M}$ (30) and Group N (30).

\section{Study Center}

The study was conducted at Department of Anaesthesiology, Chalmeda AnandRao Institute of Medical Sciences, Karimnagar during from June 2017 to October 2018.

\section{Inclusion Criteria}

- ASA grade 1

- Elective caesarean section

- All preoperative investigations to be within normal limits.

\section{Exclusion Criteria}

- Patient's refusal of procedure.

- Infections at the site of procedure.

- Hypothyroidism

- Gestational diabetes. 


\section{Study tools}

Structured questionnaire, Spinal anaesthesia equipment, Bupivacaine ampoules, Magnesium sulphate ampoules and Normal saline.

\section{Procedure}

Total 60 subjects who are undergoing elective caesarean section for establishing the efficacy of magnesium sulfate as a useful adjuvant to spinal anaesthesia in ceaserean section for prolonged postoperative analgesia. We had divided 60 subjects into 2 groups, Group $\mathrm{M}$ and Group $\mathrm{N}$ with equal number of subjects and to Group $\mathrm{M}$ given Inj $0.5 \%$ hyperbaric bupivacaine $2 \mathrm{cc}(10 \mathrm{mg})+0.1 \mathrm{cc}$ of Magnesium sulfate and to Group $\mathrm{N}$ we given Inj $0.5 \%$ hyperbaric bupivacaine $2 \mathrm{cc}(10 \mathrm{mg})+0.1 \mathrm{cc}$ of Normal saline.

\section{Ethical Approval}

This study was approved by Institute Ethics committee, Chalmeda Anand Rao Institute of Medical Sciences, Karimnagar, Telangana.

\section{Statistical Analysis}

All the data's were analyzed by Microsoft excel 2016 and SPSS version 23

\section{Results}

Table 1: Distribution of study population according to their age groups

\begin{tabular}{|c|c|c|c|}
\hline $\begin{array}{l}\text { Age } \\
\text { Groups }\end{array}$ & $\begin{array}{l}\text { Bupivacaine + } \\
\text { MgSo4 }\end{array}$ & $\begin{array}{l}\text { Bupivacaine +Normal } \\
\text { Saline }\end{array}$ & p-value \\
\hline $20-25$ years & $15(50 \%)$ & $10(33.3 \%)$ & \multirow{4}{*}{0.39} \\
\hline $25-30$ years & $7(23.3 \%)$ & $8(26.7 \%)$ & \\
\hline$>30$ years & $8(26.7 \%)$ & $12(40 \%)$ & \\
\hline Total & $30(100 \%)$ & $30(100 \%)$ & \\
\hline
\end{tabular}

Table 2: Distribution of study population according to their age groups

\begin{tabular}{|l|l|l|l|l|}
\hline Age & $\begin{array}{l}\text { Bupivacaine } \\
+ \text { MgSo4 }\end{array}$ & $\begin{array}{l}\text { Bupivacaine + } \\
\text { Normal Saline }\end{array}$ & $\begin{array}{l}\text { t- } \\
\text { value }\end{array}$ & $\begin{array}{l}\text { p- } \\
\text { Value }\end{array}$ \\
\hline Mean & 25.99 & 27.59 & \multirow{2}{*}{2.00} & \multirow{2}{*}{0.16} \\
\cline { 1 - 2 } SD & 4.22 & 4.56 & \\
\hline \multicolumn{2}{|l|}{$27.00 \pm 4.43$} & & \\
\hline
\end{tabular}

[Table 2] shows the mean age in $\mathrm{MgSo} 4+$ Bupivacaine group was 25.99 years and the SD was 4.22 , in the Bupivacaine + Saline water group the mean age was 27.59 years and the SD was 4.56. The distribution of study samples by age groups was similar in the both groups $(\mathrm{p}=0.39)$. The mean age in the three groups is comparable $(\mathrm{t}-2.00, \mathrm{P}$ $0.16)$.

Table 3: Comparison of Mean time of Onset time of sensory Block in two groups

\begin{tabular}{|l|l|l|l|l|}
\hline $\begin{array}{l}\text { Height of } \\
\text { Sensory block }\end{array}$ & $\begin{array}{l}\text { Bupivacain } \\
\text { e+MgSo4 }\end{array}$ & $\begin{array}{l}\text { Bupivacaine + } \\
\text { Normal Saline }\end{array}$ & $\begin{array}{l}\text { t- } \\
\text { value }\end{array}$ & p-Value \\
\cline { 1 - 3 } Mean & 9.97 & 5.7 & \multirow{2}{*}{-7.38} & \multirow{2}{*}{$0.001 * *$} \\
\hline SD & 3.00 & 0.99 & & \\
\hline Total & \multicolumn{2}{|c|}{$7.8 \pm 3.08$} & \\
\hline
\end{tabular}

[Table 3] shows the mean time to attain maximum level of sensory block was 9.97 mins in the $\mathrm{MgSo} 4+$ Bupivacaine group. It was 5.7 mins in the Bupivacaine + Normal Saline group, after applying t-test the difference in mean between groups was found to be significant.

Table 4: Comparison of two groups according to mean duration of 4 dermatome block

\begin{tabular}{|l|l|l|l|l|}
\hline $\begin{array}{l}\text { Height of } \\
\text { Sensory } \\
\text { block }\end{array}$ & $\begin{array}{l}\text { Bupivacaine } \\
\text { +MgSo4 }\end{array}$ & $\begin{array}{l}\text { Bupivacaine + } \\
\text { Normal Saline }\end{array}$ & $\begin{array}{l}\text { t- } \\
\text { value }\end{array}$ & p-Value \\
\hline Mean & 119.14 & 57.42 & \multirow{2}{*}{35.64} & $0.001^{* *}$ \\
\hline SD & 8.54 & 4.10 & & \\
\hline
\end{tabular}

[Table 4] shows the mean duration of 4 dermatome block was 119.14 mins in the MgSo4 + Bupivacaine group. It was 57.42 mins in the Bupivacaine + Normal Saline group after applying t-test the difference in mean between groups was found to be significant.

\begin{tabular}{|c|c|c|c|c|}
\hline \multicolumn{5}{|c|}{$\begin{array}{l}\text { Table 5: Comparison of mean Duration of Motor Block in two } \\
\text { groups }\end{array}$} \\
\hline $\begin{array}{l}\text { Mean } \\
\text { duration } \\
\text { of Motor } \\
\text { Block }\end{array}$ & $\begin{array}{l}\text { Bupivacaine } \\
+ \text { MgSo4 }\end{array}$ & $\begin{array}{l}\text { Bupivacaine + } \\
\text { Normal Saline }\end{array}$ & $\begin{array}{l}\text { t- } \\
\text { value }\end{array}$ & p-Value \\
\hline Mean & 108.78 & 53.25 & & \\
\hline SD & 6.29 & 3.27 & 42.84 & $0.001 * *$ \\
\hline
\end{tabular}

[Table 5] shows the mean duration motor block was 108.78 mins in the MgSo4 + Bupivacaine group. It was 53.25 mins in the Bupivacaine + Normal Saline group after applying ttest the difference in mean between groups was found to be significant.

Table 6: Comparison of two groups according to their mean duration of effective analgesia (min)

\begin{tabular}{|l|l|l|l|l|}
\hline $\begin{array}{l}\text { Mean } \\
\text { Duration } \\
\text { of } \\
\text { effective } \\
\text { analgesia } \\
\text { (min) }\end{array}$ & $\begin{array}{l}\text { Bupivacaine } \\
+ \text { MgSo4 }\end{array}$ & $\begin{array}{l}\text { Bupivacaine + } \\
\text { Normal Saline }\end{array}$ & $\begin{array}{l}\text { t- } \\
\text { value }\end{array}$ & p-value \\
\hline Mean & 263.09 & 136.86 & 13.67 & $0.001^{* *}$ \\
\hline SD & 15.81 & 7.29 & 13.67 \\
\hline
\end{tabular}

[Table 6] shows the mean duration effective analgesia was 263.09 mins in the MgSo4 + Bupivacaine group. It was 136.86 mins in the Bupivacaine + Normal Saline group after applying t-test the difference in mean between groups was found to be significant.

\section{Discussion}

A study conducted in tertiary care hospital, Chalmeda Anand Rao Institute of Medical Sciences, Karimnagar on comparison of intrathecal $0.5 \%$ hyperbaric bupivacaine with magnesium sulphate versus $0.5 \%$ hyperbaric bupivacaine with normal saline in elective caesarean section with 60 patients taken into study and divided into two groups of 30 each, Group M who are given Bupivacaine and magenesium sulphate and Group $\mathrm{N}$ are given bupivacaine and normal saline as spinal anaesthesia.

In our study, included age groups above 20 years and patients who are given bupivacaine and magnesium sulphate as spinal anaesthesia are 15 patients are in between age group 20-25 years, 7 are in age group 25-30 years and 8 are 
in age group above 30 years. Similarly patients who are given bupivacaine and normal saline as spinal anaesthesia are 10 patients are in between age group 20-25 years, 8 are in age group 25-30 years and 12 are in age group above 30 years. Mean age of group $M$ (Bupivacaine + Magenesium sulphate) is $25.99+/-4.22$ and that of Group $\mathrm{N}$ (Bupivacaine + Normal saline) is $27.59+/-4 .^{[7]}$

A similar study conducted by Gholamreza Khalili and Mohsen Janghorbani et al. on Effects of adjunct intrathecal magnesium sulfate to bupivacaine for spinal anesthesia: a randomized, double-blind trial in patients undergoing lower extremity surgery with 79 patients of which Group 1 (40 patients are given Bupivacaine and Magnesium sulphate) and Group 2 (39 patients) were given Bupivacaine with normal saline), group 1 has mean age group of $36.4+/-14.6$ and group 2 has mean age group $41.3+/-16.2 .44$. $^{[8]}$

Nadia Banihashem and Bahman Hasannasab et al. study showed that on Addition of Intrathecal Magnesium Sulfate to Bupivacaine for Spinal Anesthesia in Caesarean Section taken 2 groups with 40 patients each with one magnesium sulphate group and another control group with bupivacaine and normal saline showed mean age in mgso4 group as 26.88 $+/-4.44$ and control group with mean age $27.48+/-4.49$. $^{[9]}$

In the present study, the compared Mean time of Onset time of sensory Block in two groups, group M (Bupivacaine + Magenesium sulphate) showed $9.97+/-3.00$ minutes of onset which is delayed than Group N( Bupivacaine + Normal saline) which is $5.7+/-0.99$ minutes for onset of sensory block. Hence magnesium sulphate as adjuvant shows delayed onset of time of sensory block which is highly significant.

In our study, the compared mean duration of 4 dermatome block regressions in our 2 groups which shows $119.14+$ 8.54 minutes in group $M$ (Bupivacaine + Magenesium sulphate) and $57.42+/-4.10$ minutes in group $\mathrm{N}$ (Bupivacaine + Normal saline) which is more in addition of mgso4 to bupivacaine and is highly significant.

By comparing mean duration of Motor Block in two groups in our study showed $108.78+/-6.29$ minutes for group M (Bupivacaine + Magenesium sulphate) and $53.25+/-3.25$ minutes for group N (Bupivacaine + Normal saline) which implies that mean duration of motor block is prolonged in case of adding magnesium sulphate as adjuvant to bupivacaine in spinal anaesthesia which is highly significant. We compared two groups according to their mean duration of effective analgesia (min) which showed that in group $\mathrm{M}$ (Bupivacaine + Magenesium sulphate) had effective analgesia for about $263.09+/-15.81$ minutes and group $\mathrm{N}$ (Bupivacaine +Normal saline) had effective analgesia for about $136.88+/-7.29$ minutes which implies that duration of effective analgesia is prolonged in case of addition magnesium sulphate as an adjuvant which is also highly significant.

In our study, compared haemodynamic parameters such as pulse rate, Systolic blood pressure and diastolic blood pressure during the procedure up to $240 \mathrm{~min}$ which is not changed by adding Magnesium sulphate as an adjuvant in any of the parameters. Charu JP, Shivang C. Joshi et al. study also showed that addition of $\mathrm{MgSo} 4$ has no significant effect on mean pulse rate and mean arterial blood pressure. ${ }^{[9]}$

\section{Conclusion}

We conclude that Magnesium sulphate is very effective if used as an adjuvant to Bupivacaine in spinal anaesthesia as there is delayed onset of sensory block compared to Bupivacaine+ Normal saline, increased duration of 4 dermatome block regressions, increased duration of motor block and significant higher duration of effective analgesia without any alteration of hemodynamic parameters.

\section{References}

1. Roelants F. The use of neuraxial adjuvant drugs (neostigmine, clonidine) in obstetrics. Curr Opin Anaesthesiol. 2006; 19(3):233-7.

2. Rasooli S, Parish M, Mahmoodpoor A, Moslemi F, Sanaie S. Effect of spinal low dose bupivacaine-sufentanyl for caesarean section in preeclamptic parturients on neonatal outcome. Shiraz E Med J. 2009; 10(4):201-8.

3. Morrison AP, Hunter JM, Halpern SH, Banerjee A. Effect of intrathecal magnesium in the presence or absence of local anaesthetic with and without lipophilic opoids: systematic review and meta analysis. Br J Anaesthesia 2013; 110(5):702-12.

4. Saxena AK, Arava SK. Current concepts in neuraxial administration of opioids and non-opioids: An overview and future perspectives. Indian J Anaesth. 2004; 48(1):13-24.

5. Faiz SH, Rahimzadeh P, Imani F, Bakhtiari A. Intrathecal injection of magnesium sulfate: shivering prevention during caesarean section: a randomized, double-blinded, controlled study. Korean J Anesthesiol. 2013; 65(4):293-8.

6. Lee AR, Yi HW, Chung IS, Ko JS, Ahn HJ, Gwak MS, et al. Magnesium added to bupivacaine prolongs the duration of analgesia after interscalene nerve block. Can J Anaesth. 2012; 59(1):21-7.

7. Praveen K Donadi, Srilata Moningi, Ramachandran Gopinath, Comparison of bupivacaine and bupivacaine plus magnesium sulphate infiltration for postoperative analgesia in patients undergoing lumbar laminectomy: A prospective randomized double blinded controlled study. J NeuroAnaesthesiol Critical Care. 2014; 1(3):183-187.

8. Gholamreza Khalili, Mohsen Janghorbani et al. Effects of adjunct intrathecal magnesium sulfate to bupivacaine for spinal anesthesia: a randomized, double-blind trial in patients undergoing lower extremity surgery; J Anesth. 2011; 25:892-897.

9. Nadia Banihashem, Bahman Hasannasab et al. Addition of Intrathecal Magnesium Sulfate to Bupivacaine for spinal Anesthesia in caesarean Section. Anesth Pain Med. 2015; 5(3):e22798.

10. Charu J. Pandya, Shivang C. Joshi et al. A Comparative study of Bupivacaine and Bupivacaine with Magnesium Sulphate in spinal Anesthesia for lower abdominal surgery. Int J Scientific Res. 201; 2(7):276-278.

Copyright: () the author(s), publisher. Academia Anesthesiologica International is an Official Publication of "Society for Health Care \& Research Development". It is an open-access article distributed under the terms of the Creative Commons Attribution Non-Commercial License, which permits unrestricted non-commercial use, distribution, and reproduction in any medium, provided the original work is properly cited.

How to cite this article: Kishore K, Reddy IRK, Kumar K K. A Comparative Study of Intrathecal $0.5 \%$ Hyperbaric Bupivacaine with Magnesium Sulfate versus $0.5 \%$ Hyperbaric Bupivacaine with Normal Saline in Elective Caesarean sections. Acad. Anesthesiol. Int. 2019;4(1):90-92.

DOI: dx.doi.org/10.21276/aan.2019.4.1.20

Source of Support: Nil, Conflict of Interest: None declared. 